\title{
DESAFIOS PARA AS CIDADES SUSTENTÁVEIS: A PARTICIPAÇÃO PÚBLICA EM MATÉRIA AMBIENTAL COMO PILAR DO PLANO DIRETOR
}

\author{
Lívia Gaigher Bósio Campello ${ }^{1}$ \\ Rafaela de Deus Lima ${ }^{2}$ \\ Rodrigo de Oliveira Ferreira ${ }^{3}$
}

\section{RESUMO:}

O presente artigo analisa a importância da participação pública ambiental no Plano Diretor frente aos desafios para as cidades sustentáveis. Nesse intuito, expõem-se problemas socioambientais existentes e verifica-se a importância do direito fundamental ao meio ambiente em prol da sustentabilidade urbana. Em conclusão, verifica-se que a Constituição Federal, o Estatuto da Cidade e o Plano Diretor garantem a participação pública em matéria ambiental, salientando-se o direito-dever de todos na proteção e preservação do meio ambiente. Para tanto, utiliza a pesquisa exploratória e descritiva, bibliográfica e documental, com uma análise de obras, artigos científicos e legislações. $\mathrm{O}$ método é dedutivo.

Palavras-chave: Cidades sustentáveis; urbanização; direito fundamental ao meio ambiente; participação pública; plano diretor.

\section{CHALLENGES OF THE SUSTAINABLE CITIES: PUBLIC PARTICIPATION IN ENVIRONMENTAL MATTERS AS A PILLAR OF THE MASTER PLAN}

\begin{abstract}
:
This article analyzes public environmental participation's importance in the Master Plan in view of the challenges for sustainable cities. To that end, existing socio-environmental problems are exposed and the importance of the fundamental right to the environment is verified in favor of urban sustainability. In conclusion, it appears that the Federal Constitution, the City Statute and the Master Plan guarantee public participation in

\footnotetext{
${ }^{1}$ Pós-Doutora em Direito do Estado pela Universidade de São Paulo (USP). Doutora em Direito das Relações Econômicas e Internacionais pela Pontifícia Universidade Católica de São Paulo (PUC/SP) e Mestre em Políticas Públicas e Processo pelo Centro Universitário Fluminense (UNIFLU). Professora da graduação e mestrado na Faculdade de Direito (FADIR/UFMS). Coordenadora do Programa de Pós-Graduação em Direitos Humanos (PPGD/UFMS). Coordenadora local do Programa de Doutorado Interinstitucional (DINTER - USP/UFMS). Líder do Grupo de Pesquisa "Direitos Humanos, Meio Ambiente e Desenvolvimento Sustentável Global" (UFMS/CNPq). Editora-chefe da Revista Direito UFMS. Associada ao Conselho Nacional de Pesquisa e PósGraduação (CONPEDI) desde 2005. Filiada à Sociedade Brasileira para o Progresso da Ciência (SBPC) desde 2011. E-mail: liviagaigher@gmail.com

${ }_{2}^{2}$ Mestranda do Programa de Pós-Graduação em Direito da Universidade Federal de Mato Grosso do Sul (PPGDUFMS). Bolsista CAPES. Graduada em Direito pela Universidade Federal de Mato Grosso do Sul (FADIRUFMS). Assistente Editorial da Revista Direito UFMS Integrante do Grupo de Pesquisa "Direitos Humanos, Meio Ambiente e Desenvolvimento Sustentável Global (CNPq-UFMS). E-mail: rafaeladedeuslima@ gmail.com.

${ }^{3}$ Mestrando do Programa de Pós-Graduação em Direito da Universidade Federal de Mato Grosso do Sul (PPGD-UFMS). Graduada em Direito pela Universidade Estadual de Mato Grosso do Sul (FADIR-UFMS). Especialista em Direito Público e Direito Municipal pela Universidade Anhanguera-Uniderp. Integrante do Grupo de Pesquisa "Direitos Humanos, Meio Ambiente e Desenvolvimento Sustentável Global (CNPq-UFMS). Procurador do Município de Ponta Porã, MS. E-mail: rodrigo_ferreira@ufms.br
} 
environmental matters, emphasizing the right-duty of everyone to protect and preserve the environment. For this, it uses exploratory and descriptive, bibliographic and documentary research, with an analysis of works, scientific articles and legislation. The method is deductive.

Keywords: Sustainable cities; urbanization; fundamental right to the environment; public participation; master plan

\section{INTRODUÇÃO}

As cidades têm grande relevância no que concerne às atividades humanas, podendo funcionar como centros econômicos, sociais e culturais. Todavia, o modo desordenado como muitos centros urbanos se organizaram colaborou para a emergência de inúmeros problemas ambientais que acabam prejudicando o bem-estar de sua população.

Atualmente, as cidades, no contexto mundial, enfrentam desafios ligados ao acesso à água e saneamento básico, assentamentos urbanos irregulares, à gestão de resíduos sólidos e poluição atmosférica. Tais problemáticas também fazem parte da realidade urbana brasileira, revelando um processo de urbanização sem planejamento pautado na exploração do meio ambiente e causando, consequentemente, uma profunda pressão nos ecossistemas.

O devido enfrentamento dessas questões demanda uma visão holística que harmonize os fatores ambientais, sociais e econômicos, colocando a proteção do meio ambiente e a ideia de sustentabilidade como um imperativos para o futuro dos ordenamentos urbanos. Com efeito, a participação pública destaca-se como mecanismo democrático importante no que concerne à proteção dos interesses coletivos no contexto do desenvolvimento sustentável urbano. Nesse panorama, questiona-se qual a importância dos instrumentos de participação pública em matéria ambiental no Plano Diretor frente aos desafios para as cidades sustentáveis.

Para tanto, o presente artigo tem como objetivo geral verificar a participação pública em matéria ambiental como um pilar do Plano Diretor frente aos desafios à sustentabilidade no ordenamento urbano. Como objetivos específicos, buscar-se-á: elencar os principais desafios ambientais emergentes no contexto urbano brasileiro; verificar a importância da garantia do direito fundamental ao meio ambiente em prol da sustentabilidade urbana e, por fim, analisar a participação pública ambiental enquanto pilar do Plano Diretor. 
A fim de alcançar os objetivos mencionados, será utilizada a pesquisa exploratória e descritiva, bibliográfica e documental, com uma análise por meio de obras, artigos científicos e legislações nacionais. O método de abordagem será o dedutivo, partindo de conceitos gerais até sua particularização.

\section{OS DESAFIOS AMBIENTAIS NO CONTEXTO URBANO BRASILEIRO}

Nas últimas décadas verificou-se grande progresso e avanço dos centros urbanos; o número de pessoas vivendo em cidades está em constante crescimento e apresenta-se como uma tendência para o futuro. Atualmente, $55 \%$ da população mundial vive em centros urbanos, sendo que, até 2050, estima-se que as cidades irão abrigar $70 \%$ da população (ONU NEWS, 2019). Essa tendência também se repete no cenário brasileiro, em que mais de $84 \%$ da população vive em cidades (IBGE EDUCA, 2015).

Todavia, o desenvolvimento desses centros deu-se, muitas vezes, de modo rápido e desordenado, o que colaborou para o desencadeamento de inúmeras problemáticas ambientais no âmbito das cidades, as quais influenciam diretamente no bem-estar da população. Não obstante, tais questões tornam-se ainda mais emergenciais frente ao iminente aumento do número de pessoas que habitarão os centros urbanos.

O ordenamento urbano brasileiro também enfrenta inúmeros problemas socioambientais, dentre os quais se destacam o acesso à água e ao saneamento básico, a gestão de resíduos sólidos, a ordenação dos assentamentos urbanos, a mobilidade urbana e a poluição atmosférica. Esse quadro revela uma ausência de implementação efetiva da legislação existente e a falta de uma gestão que considere as demandas sociais e ambientais das cidades.

A água potável é fundamental para assegurar o bem-estar populacional e para o pleno desenvolvimento humano; entretanto, o acesso a esse recurso natural continua sendo um desafio no Brasil. Dados divulgados Sistema Nacional de Informações sobre Saneamento (SNIS), referentes a 2018, demonstram que mais de 16\% da população, ou quase 35 milhões de pessoas, não têm acesso à água tratada (SNIS, 2019).

Ademais, conforme estudos realizados pelo Instituto Brasileiro de Geografia e Estatística (IBGE), quase 10\% dos domicílios brasileiros não contam com o abastecimento de água diariamente; em 5\% deles, a frequência de abastecimento era de quatro a seis vezes por 
semana, enquanto em outros $4,9 \%$ a água era fornecida apenas por até três dias semanais (IBGE, 2019).

No que tange ao saneamento básico no Brasil, o país ainda está muito longe de alcançar sua universalização. As cidades brasileiras registram, aproximadamente, 68,3\% de domicílios com esgotamento sanitário (rede geral ou fossa séptica ligada à rede) (IBGE, 2019). O estudo realizado pela Associação Brasileira de Engenharia Sanitária e Ambiental (ABES) aponta que, dentre os 5.570 municípios brasileiros, menos de 100 encontram-se perto de universalizar o serviço de saneamento básico (VELASCO, 2020).

O tratamento do esgoto recolhido é outro ponto crítico no contexto brasileiro, uma vez que apenas $46 \%$ passa pelo devido processo de tratamento (SNIS, 2019). O Ranking do Saneamento 2019, organizado pelo Instituto Trata Brasil, aponta que, no ano de 2017, o país lançou aproximadamente 5.622 piscinas olímpicas de esgoto não tratado na natureza (TRATA BRASIL, s. d.).

Outra adversidade que também suscita preocupações nas cidades brasileiras refere-se ao manejo dos resíduos sólidos urbanos. O último relatório da Associação Brasileira de Empresas de Limpeza Pública e Resíduos Especiais (Abrelpe) aponta que, no Brasil, as cidades geraram, em 2018, cerca de 79 milhões de toneladas de resíduos sólidos urbanos cuja coleta alcançou $92 \%$ desse total $^{4}$ (IPEA, 2020). Ainda, importa salientar que, dentre os municípios brasileiros, apenas 38,1\% apresenta serviços de coleta seletiva (SNIS, 2018), demonstrando uma clara defasagem no que concerne à recuperação desses resíduos.

Dentre as problemáticas referentes ao ordenamento urbano, outra que se apresenta de maneira recorrente e está presente em diversas cidades brasileiras concerne aos assentamentos urbanos informais. Comunidades inteiras, especialmente, as mais pobres e sem condições suficientes, adequadas e acessíveis de acesso à terra urbana e à moradia, ocupam irregular e inadequadamente o meio ambiente urbano, instalam-se em lugares de difícil acesso, com ausência de planejamento urbano, de infraestrutura básica, como água, luz e esgoto, distantes de escolas e do serviço de saúde pública e sem linhas de transporte público com acesso a esses locais.

Esses assentamentos acarretam a consequente falta de segurança da posse e baixa qualidade de vida dos seus ocupantes, deixando a população, ali instalada, vulnerável a vários

${ }^{4}$ Aproximadamente 72 milhões de toneladas. 
problemas sanitários. As cidades brasileiras são fortemente marcadas pela presença dos assentamentos informais, vilas, loteamentos clandestinos e favelas, os quais se constituem em espaços irregulares, vulneráveis e inseguros, em que vive grande parte da população.

A irregularidade no país passou a ser regra e não exceção; estimativas realizadas pela Secretaria Nacional de Programas Urbanos indicam que mais de 12 milhões de domicílios urbanos ocupados por população de baixa renda são irregulares (MPGO, s. d.); com efeito, esse cenário enfatiza a necessidade de promover a regularização fundiária dos assentamentos irregulares, o que somente é possível por intermédio do correto parcelamento do solo urbano com a devida previsão nos Planos Diretores das cidades.

Por fim, outra questão que levanta inúmeros desafios no contexto das cidades concerne à poluição atmosférica, cuja preocupação é tema de discussões nas últimas décadas. Trata-se de uma problemática global que, conforme indica a Organização Mundial da Saúde (OMS), ocasiona uma mortalidade de 7 milhões de pessoas todos os anos (2018) gerando, também, efeitos negativos no contexto econômico e social.

No Brasil, de acordo com o Ministério da Saúde (2019), as mortes em decorrência da poluição atmosférica aumentaram $14 \%$ em dez anos. Nesse período, o número de óbitos por Doenças Crônicas não Transmissíveis (DCNT) passou de 38.782, em 2006, para 44.228 mortes em 2016, tal constatação foi realizada pelo estudo Saúde Brasil 2018, do Ministério da Saúde, que utilizou dados do Sistema de Informações sobre Mortalidade (SIM). O número de mortes evitáveis por essas doenças cresceu, assim como a exposição à poluição do ar em todo o país, com destaque para os grandes centros urbanos e os estados castigados pelas queimadas.

O transporte é o principal fator causador da poluição atmosférica nos centros urbanos, estando intimamente ligado ao aumento da concentração de gases poluentes. Atualmente, o Brasil conta com uma frota de 54 milhões de automóveis, 11 milhões de caminhonetes e camionetas e 22 milhões de motocicletas (IBGE, 2018). Tais dados demonstram a priorização que se dá ao transporte individual e aos veículos motorizados, revelando uma baixa atenção, por parte do poder público, à mobilidade urbana e a vários princípios, diretrizes e objetivos postos pela Política Nacional de Mobilidade Urbana, os quais são voltados ao desenvolvimento sustentável das cidades (nas dimensões socioeconômicas e ambientais), à redução das desigualdades e promoção da inclusão social e do acesso aos serviços básicos e equipamentos sociais. 
A referida problemática, atualmente, também é agravada pelas queimadas recorrentes na Floresta Amazônica e no Pantanal Mato-Grossense, pois a poluição atmosférica gerada pela queimada nesses biomas impacta, diretamente, no âmbito das cidades; o que pode ser exemplificado pelo escurecimento do céu na cidade de São Paulo, em 2019, a qual foi surpreendida com a presença de uma névoa escura que causou a chegada de uma frente fria. Segundo institutos brasileiros de pesquisa climática, como o Climatempo (2019), e o Instituto Nacional de Meteorologia (INMET, 2019) as queimadas da região norte seriam uma das causas do fenômeno.

Em 2020, a situação também é de alerta, os dados do Instituto Nacional de Pesquisas Espaciais (INPE) demonstram que os focos de incêndio, até o mês de setembro, já superam a quantidade observada em todo o ano de 2019. Tais queimadas são responsáveis pelo aumento das estatísticas apresentadas pelo Ministério da Saúde, pois, certamente, causam, além do dano ambiental, danos à saúde da população local e de outras cidades, igualmente atingidas pela poluição atmosférica e a consequente perda da qualidade do ar.

No Brasil, o Conselho Nacional do Meio Ambiente (CONAMA) é responsável pela regulamentação, fiscalização e controle da qualidade do ar e o faz por meio de Resoluções e não por lei em sentido estrito. As resoluções, no entanto, não podem regulamentar, por exemplo, o financiamento da fiscalização, ficando a cargo dos estados federados realizar o monitoramento. Dessa forma, não há padronização do monitoramento realizado pelos estados ou, sequer, a obrigatoriedade de fiscalização pelos estados, prejudicando o controle da poluição atmosférica e a garantia da qualidade do ar.

As problemáticas elencadas apresentam-se como grandes desafios para as cidades modernas, sendo necessário buscar respostas que possibilitem o desenvolvimento dos centros urbanos mas que não gerem externalidades ambientais e sociais que comprometam o bemestar da população e, por conseguinte, a dignidade humana.

A busca de respostas para tais questões passa, necessariamente, pelo quadro do desenvolvimento sustentável enquanto processo para enfrentar as problemáticas socioambientais e construir cidades sustentáveis que possam se desenvolver e ser mantidas para as futuras gerações. Dessa forma, é necessário o desenvolvimento de políticas públicas, instrumentos e legislações que viabilizem uma transição das cidades rumo à sustentabilidade. 


\section{O DIREITO FUNDAMENTAL AO MEIO AMBIENTE NA CONSTRUÇÃO DE CIDADES SUSTENTÁVEIS}

A afirmação dos direitos humanos e dos direitos fundamentais verifica-se no transcorrer da história por intermédio de um longo processo de lutas e conquistas da humanidade ao buscar resguardar valores socialmente relevantes para a dignidade humana, traduzindo "[...] uma sucessão de batalhas diretas e indiretas pela abertura de espaços diante do poder estabelecido [...]" (SILVEIRA; ROCASOLANO, 2010, p. 185). Em mesmo sentido, Bobbio (2004, p. 05) afirma que:

os direitos do homem, por mais fundamentais que sejam, são direitos históricos, ou seja, nascidos em certas circunstâncias, caracterizadas por lutas em defesa de novas liberdades contra velhos poderes, e nascidos de modo gradual, não todos de uma vez e nem de uma vez por todas.

O surgimento desses direitos decorre de um processo dinâmico denominado, conforme explicam Silveira e Rocasolano (2010), dinamogenesis, em que determinados valores são descobertos pela sociedade e vislumbrados como relevantes, o que ocasiona, posteriormente, sua positivação no ordenamento jurídico.

Logo, a evolução dos direitos humanos e dos direitos fundamentais é resultado da realidade e dos valores sociais da época em que foram considerados importantes e, por conseguinte, afirmados no ordenamento jurídico; ou seja, é produto do que cada sociedade entende como justo e valioso em determinado momento histórico. Com efeito, "os valores, [...], são o fundamento e o motor de uma sociedade e de uma cultura e, consequentemente, o conteúdo da dignidade vital das pessoas e das nações que representam - ou seja, o núcleo existencial dos direitos humanos" (SILVEIRA; ROCASOLANO, 2010, p. 191 -192).

Nesse sentido, Sarlet e Fensterseifer (2020, p. 223) afirmam que:

O processo histórico-civilizatório das sociedades determina e legitima os direitos que devem integrar o rol destacado dos direitos fundamentais, tendo-se em conta o horizonte normativo-conceitual mutável, inacabado e aberto materialmente em face dos novos desafios existenciais postos a cada avanço civilizatório.

Trata-se, portanto, de um processo histórico que se encontra em contínua construção, demonstrando que "a sociedade modifica e incorpora novos valores na medida em que as demandas históricas a impulsionam para novos caminhos e necessidades, objetivando 
essencialmente a proteção e a plena realização de uma vida humana digna e saudável para todos os seus membros ${ }^{5}$ [...]" (SARLET; FENSTERSEIFER, 2020, p. 223).

Com efeito, não há dúvida de que a afirmação do direito fundamental (e humano) ao meio ambiente saudável e equilibrado também decorre de um processo histórico e tem uma base axiológica resultante do "[...] despertar da consciência ecológica mediante práticas sociais [que consolidaram] os valores ecológicos no espaço político, alcançando, posteriormente, também o universo jurídico" (SARLET; FENSTERSEIFER, 2020, p. 73).

$\mathrm{O}$ direito fundamental (e humano) ao meio ambiente "[...] ajusta-se aos novos enfrentamentos históricos de natureza existencial postos pela degradação e poluição ambiental em prejuízo do pleno desenvolvimento da vida humana, [...]” (SARLET; FENSTERSEIFER, 2020, p. 228), enquadrando-se nos direitos de terceira dimensão (ou geração), cuja matriz axiológica fundamenta-se na solidariedade.

Nesse sentido, o direito ao meio ambiente preocupa-se com os interesses de toda a coletividade, não se restringindo ao indivíduo ou determinado grupo social, nem mesmo aos limites territoriais dos Estados, tendo em vista a ubiquidade do bem ambiental. Assim, "o direito fundamental ao meio ambiente, em sintonia com sua natureza transindividual, apresenta caráter transfronteiriço ou supranacional [...], já que transporta implicações de escala global e universal [...]" (SARLET; FENSTERSEIFER, 2020, p. 232).

Com efeito, a proteção do meio ambiente, na qualidade de direito humano, encontra sua afirmação e positivação tanto no âmbito internacional quanto regional e nacional. No ordenamento jurídico brasileiro, o direito fundamental ${ }^{6}$ ao meio ambiente foi previsto no artigo 225 da Constituição Federal de 1988 (CF/88), determinando que "todos têm direito ao meio ambiente ecologicamente equilibrado, bem de uso comum do povo e essencial à sadia qualidade de vida, impondo-se ao Poder Público e à coletividade o dever de defendê-lo e preservá-lo para as presentes e futuras gerações” (BRASIL, 1988).

\footnotetext{
5 “Cada dimensão de direitos fundamentais representa a 'fotografia' constitucional de um dado momento e contexto histórico, considerando-se que o registro fotográfico e a revelação de novas 'fotos' devam ser constantes a fim de acompanhar os novos enfrentamentos constitucionais formulados permanentemente diante da busca de uma salvaguarda cada vez maior do ser humano a cada etapa evolutiva e dialética da nossa História civilizatória" (SARLET; FENSTERSEIFER, 2020, p. 224).

${ }^{6}$ A despeito de não estar presente no art. $5^{\circ}$ da $\mathrm{CF} / 88$, o direito ao meio ambiente é um direito fundamental. Sua previsão na ordem econômica (art. 170, VI) e a previsão de que a proteção ao meio ambiente é um dever de todos (art. 225) garantem aos cidadãos a proteção e promoção da dignidade, pois o desfrute da qualidade ambiental passa a ser identificado como elemento indispensável ao pleno desenvolvimento da pessoa humana, atribuindo ao direito ao ambiente o status de direito fundamental do indivíduo e da coletividade.
} 
A CF/88 inaugura o regime constitucional-ecológico brasileiro ao positivar, no ordenamento jurídico nacional, o direito fundamental ao meio ambiente. Trata-se de um relevante marco normativo pois, além de tutelar o equilíbrio ecológico, assegura o direito ao meio ambiente com ênfase no valor de solidariedade intra e intergeracional, reconhecendo que sua preservação e defesa deve ser efetuada tanto em prol dos interesses das presentes gerações quanto das futuras.

Importa destacar que o texto constitucional, ao tratar do meio ambiente no referido artigo, não buscou apenas assegurar o meio ambiente ecologicamente equilibrado para todas as pessoas, mas também incorporou a ideia de dever-fundamental, uma vez que a redação do dispositivo mencionado é clara ao impor ao Poder Público e à coletividade o dever de proteger e defender o meio ambiente.

Consequentemente, estrutura-se o direito-dever fundamental ao meio ambiente, ou seja, por um lado tem-se o direito subjetivo ao meio ambiente, mas, por outro, ao seu titular e ao Poder Público impõem-se deveres gerais de melhoria progressiva da qualidade ambiental frente às presentes e futuras gerações, sendo uma expressão clara do meio ambiente enquanto direito-dever fundamental pautado na solidariedade.

Todavia, a melhoria progressiva da qualidade ambiental e a garantia do direito fundamental ao meio ambiente não deve ser vislumbrada isoladamente das questões sociais e econômicas que também demandam respostas na contemporaneidade. Nesse contexto, aliada com a proteção ambiental, importa destacar a noção de sustentabilidade, asseverando que "a preservação e utilização sustentável e racional dos recursos ambientais devem ser encaradas de modo a assegurar um padrão constante de elevação da qualidade de vida, sendo, portanto, o fator econômico encarado como desenvolvimento, e não como crescimento" (SARLET; FENSTERSEIFER, 2020, p. 169).

A construção de uma sociedade sustentável, pautada na conciliação dos fatores ambientais, sociais e econômicos coloca-se como um grande desafio na atualidade, tanto no contexto internacional quanto nacional. Portanto:

para alcançar um estado de sustentabilidade [...], é necessário um processo. Certas condições e etapas têm de ser cumpridas em direção à "sustentabilidade". [Com efeito], o quadro do desenvolvimento sustentável é o meio para alcançar a sustentabilidade. Em suma, "sustentabilidade" refere-se à meta e "desenvolvimento sustentável” é o caminho ou mapa para alcançá-la (CAMPELLO; SILVEIRA, 2016, p. 561) 
Nesse sentido, o desenvolvimento sustentável, conceituado ${ }^{7}$ como aquele que atende as necessidades do presente sem comprometer aquelas das futuras gerações, tornou-se um imperativo das sociedades modernas, fundamentando políticas públicas e normas no ordenamento internacional, como pode ser claramente observado, por exemplo, no âmbito das declarações da ONU que colaboraram, inclusive, para a construção da Agenda 2030 e seus 17 Objetivos de Desenvolvimento Sustentável (ODS) que elencam metas tanto para os nível global quanto nacional.

A ideia de desenvolvimento sustentável e seu conceito repercutem, claramente, nos contextos jurídicos de inúmeros países. No que tange ao contexto brasileiro, o desenvolvimento sustentável ${ }^{8}$ foi incorporado no ordenamento jurídico nacional antes mesmo da constitucionalização do direito ao meio ambiente, sendo previsto como objetivo da Política Nacional do Meio Ambiente (Lei n. 6.938/81) no seu artigo $4^{9}$, incisos I e VI.

Não obstante, em 1988, o constituinte elevou a sustentabilidade a nível constitucional, sendo possível interpretar a ideia de desenvolvimento sustentável no inciso VI do artigo $170^{10}$ da $\mathrm{CF} / 88$, o qual coloca a defesa do meio ambiente como princípio da ordem econômica, integrando-a com a livre iniciativa e concorrência, a propriedade privada e a justiça social. Nesse sentido, o dispositivo expressa:

[...] uma opção pelo que se poderia designar de um capitalismo ambiental ou socioambiental [...] capaz de compatibilizar a livre-iniciativa, a autonomia e a

\footnotetext{
${ }^{7}$ O quadro contemporâneo da degradação e crise ambiental é fruto dos modelos econômicos experimentados no passado e dos equívocos que seguem sendo cometidos, gerando verdadeira crise ambiental na busca incessante do lucro a qualquer custo, especialmente nas décadas de 60 e 70. Isso despertou a consciência acerca dos limites do crescimento econômico e da esgotabilidade dos recursos naturais. O conceito de desenvolvimento sustentável foi cunhado no âmbito da Comissão Mundial sobre Meio Ambiente e Desenvolvimento das Nações Unidas, designadamente por meio do Relatório Nosso Futuro Comum (1987), veiculando a noção de que desenvolvimento sustentável seria aquele que atende às necessidades do presente sem comprometer a possibilidade de as gerações futuras atenderem a suas próprias necessidades (SARLET; FENSTERSEIFER, 2017).

${ }^{8}$ O conceito de desenvolvimento sustentável promovido pelo Relatório Brundtland foi incorporado no Princípio 4 da Declaração do Rio sobre Meio Ambiente e Desenvolvimento (1992), posteriormente, ratificada na Rio+20, que culminou na criação, pela ONU, da Agenda 2030 (2015) com 17 Objetivos do Desenvolvimento Sustentável.

9 “Art. $4^{\circ}$ - A Política Nacional do Meio Ambiente visará: I - à compatibilização do desenvolvimento econômico social com a preservação da qualidade do meio ambiente e do equilíbrio ecológico; [...] VI - à preservação e restauração dos recursos ambientais com vistas a sua utilização racional e disponibilidade permanente, concorrendo para a manutenção do equilíbrio ecológico propício à vida;” (BRASIL, 1981)

10 "Art. 170. A ordem econômica, fundada na valorização do trabalho humano e na livre iniciativa, tem por fim assegurar a todos existência digna, conforme os ditames da justiça social, observados os seguintes princípios: [...] VI - defesa do meio ambiente, inclusive mediante tratamento diferenciado conforme o impacto ambiental dos produtos e serviços e de seus processos de elaboração e prestação;" (BRASIL, 1988).
} 
propriedade privada com a proteção ambiental e a justiça social (e também justiça ambiental), tendo como norte normativo "nada menos" do que a proteção e a promoção de uma vida humana digna (e, portanto, com qualidade, equilíbrio e segurança ambiental) para todos os membros da comunidade estatal (SARLET; FENSTERSEIFER, 2020, p. 170).

Com efeito, a garantia do direito fundamental ao meio ambiente, previsto no artigo 225 da CF/88, coloca-se como fator primordial no contexto do desenvolvimento sustentável, sendo essa ideia, inclusive, verificada no próprio texto constitucional brasileiro, ao trazer, no artigo 170, a proteção do meio ambiente dentro da ordem econômica; não restando dúvidas de que a edificação de uma sociedade sustentável depende da inclusão dos fatores ambientais, em harmonia com as questões sociais e econômicas, nas políticas públicas e normas jurídicas.

Posteriormente, após sua previsão constitucional, a ideia de desenvolvimento sustentável expressou-se em inúmeras legislações ambientais brasileiras, ora como princípio orientador ou como objetivo; a título de exemplo, destacam-se a Lei da Política Nacional de Recursos Hídricos (Lei n. 9.433/91), Lei da Mata Atlântica (Lei n. 11.428/2006), Lei da Política Nacional sobre Mudança Climática (Lei n. 12.187/2009), Lei da Política Nacional de Resíduos Sólidos (Lei n. 12.305/2010) e o Código Florestal (Lei n. 12.651/2012).

Sem embargo, o enfrentamento das questões socioambientais verificadas no ordenamento urbano demanda, necessariamente, a garantia efetiva do direito fundamental ao meio ambiente ecologicamente equilibrado em conjunto com a ideia de sustentabilidade, pois problemáticas como acesso à água, falta de saneamento, poluição atmosférica e má gestão de resíduos sólidos representam uma real ameaça, não apenas ao direito ao meio ambiente, mas também aos demais direitos fundamentais assegurados no ordenamento jurídico brasileiro, bem como para a própria dignidade humana.

Frente a tais questões, as cidades devem ser organizadas com base nos interesses da coletividade, a partir de uma visão de transformação humanizadora, como espaço de materialização dos princípios de justiça social e ambiental (LEFEBVRE, 2008), enfatizando a ideia de cidades sustentáveis, as quais seriam aquelas em que o desenvolvimento econômico é compatível com a preservação ambiental e a qualidade de vida dos habitantes (CAVALAZZI, 2007).

Com efeito, as políticas e normas concernentes ao desenvolvimento urbano devem ser pautadas na sustentabilidade, conciliando os fatores ambientais, sociais e econômicos em sua elaboração. Esse imperativo pode, inclusive, ser interpretado na $\mathrm{CF} / 88$, mais especificamente 
no artigo $182^{11}$, que coloca o bem-estar e o desenvolvimento social das cidades como objetivos da política de desenvolvimento urbano.

Atualmente, não há dúvidas de que o bem-estar da população não pode ser garantido de forma plena sem um meio ambiente ecologicamente equilibrado, o próprio artigo 225 da $\mathrm{CF} / 88$ reconhece que o direito fundamental ao meio ambiente é essencial à sadia qualidade de vida; logo, o meio ambiente coloca-se como pré-requisito para assegurar o bem-estar da população que vive no contexto urbano.

Em mesmo sentido, o Estatuto da Cidade (Lei n. 11.257/2001) "estabelece normas de [...] interesse social que regulam o uso da propriedade urbana em prol do bem coletivo, [...] e do bem-estar dos cidadãos, bem como do equilíbrio ambiental” (BRASIL, 2010). Ainda, a mesma legislação coloca como diretrizes da política urbana a garantia de cidades sustentáveis e a proteção, preservação e recuperação do meio ambiente natural e construído ${ }^{12}$.

Com efeito, indubitavelmente, a garantia do direito fundamental ao meio ambiente, coloca-se como fator primordial no enfrentamento das problemáticas socioambientais que emergem no cenário urbano contemporâneo, não sendo possível que as cidades alcancem a sustentabilidade sem uma visão holística que assegure a qualidade ambiental e, por conseguinte, o bem-estar de seus cidadãos.

\section{A PARTicipação pública ambiental COMO PILAR do Plano DIRETOR DAS CIDADES SUSTENTÁVEIS}

O grande desafio da atualidade no campo dos direitos fundamentais concerne à sua proteção (BOBBIO, 2004); nesse sentido, a dimensão procedimental de tais direitos ganha relevância, uma vez que "a função do direito ao procedimento é instrumentalizar e garantir uma proteção efetiva dos direitos materiais” (SARLET; FENSTERSEIFER, 2018, p. 423).

\footnotetext{
11 Art. 182. A política de desenvolvimento urbano, executada pelo Poder Público municipal, conforme diretrizes gerais fixadas em lei, tem por objetivo ordenar o pleno desenvolvimento das funções sociais da cidade e garantir o bem- estar de seus habitantes.

12 Art. 2. A política urbana tem por objetivo ordenar o pleno desenvolvimento das funções sociais da cidade e da propriedade urbana, mediante as seguintes diretrizes gerais: I- - garantia do direito a cidades sustentáveis, [...]; [...] XII - proteção, preservação e recuperação do meio ambiente natural e construído, do patrimônio cultural, histórico, artístico, paisagístico e arqueológico;
} 
Dentre os direitos procedimentais que podem ser elencados na garantia de direitos fundamentais, destaca-se a participação pública que "cria juridicamente a possibilidade fática de uma influência no processo de formação da vontade estatal no que diz respeito à proteção do direito fundamental” (ALEXY apud SARLET; FENSTERSEIFER, 2018, p. 425).

A ideia de participação “[...] é um conceito que só é integralmente compreendido se tratado em conjunto com outros, como 'democracia', 'cidadania' e 'direitos do cidadão'” (CAMPELLO, 2014, p. 86). Portanto:

\begin{abstract}
o novo paradigma incorporado na ideia de "democracia participativa" compatibiliza as ideias de representação política e participação popular, [...], [acolhendo-se] a ideia de que a ampliação da democracia pela participação da sociedade pelo menos tempera ou aperfeiçoa os atos do governo representante. Daí, pode-se falar em "governança", refletida na busca do atendimento dos anseios e aspirações dos governados (CAMPELLO, 2014, p. 86).
\end{abstract}

Com efeito, a democracia passa a ser concebida enquanto espaço de debate público, onde as decisões relevantes da sociedade seriam tomadas por intermédio de um processo de debate e discussão junto às diversas forças que integram a sociedade civil (CAMPELLO, 2014). No contexto democrático, trazer o cidadão junto das esferas de tomada de decisões e incentivar a sua participação justifica-se, conforme Campello (2014) por seis razões principais:

Preliminarmente, pela simples e óbvia razão de alcançar o aprimoramento da governança (eficiência); em segundo lugar, para propiciar mais freios contra o poder de interesses escuros sobre o governo (legalidade); em terceiro, para garantir, sempre mais, que nenhum interesse seja negligenciado ou excluído na consideração governamental para a tomada de decisão (justiça); em quarto, para garantir, pela participação de mais pessoas informadas e sábias, que se chegue a uma sabedoria coletiva, [...], que sobrepasse mesmo a do mais sábio e prudente governante (legitimidade); em quinto, pela responsabilidade que, assim, se infunde nos indivíduos, pelas consequências de suas ações políticas, aprimorando-se pelo equilíbrio, que isto importa entre a realização de seus desejos pessoais e do interesse coletivo (civismo); sexto, para tornar o produto governamental mais aceitável e, portanto, de um lado, garantindo o mais fiel cumprimento de suas determinações e, de outro, reduzindo o risco de descontentamentos (ordem) (CAMPELLO, 2014, p. 86).

A Constituição Federal de 1988 está imbuída pela ideologia participativa, espelhando claro resultado do movimento democrático-popular que se instaurou nas capitais brasileiras na época da Assembleia Nacional Constituinte. Essa ideologia: 
fica evidente não só pela inclusão de mecanismos de participação direta [...] e a substituição da fórmula 'todo poder emana do povo e em seu nome será exercido', pela frase 'todo poder emana do povo que o exerce por meio de seus representantes eleitos ou diretamente, nos termos desta constituição', mas também, porque ao longo do texto constitucional foram incorporados princípios gerais que estabelecem as bases gerais para a participação da população na gestão da coisa pública (CALDERÓN apud CAMPELLO, 2014, p. 94).

No tocante ao contexto ambiental, a participação pública é essencial na garantia do meio ambiente ecologicamente equilibrado, pois "na medida que a degradação ambiental em termos locais, regionais e planetários aproxima-se de um quadro limite e preocupante, não se pode conceber um cidadão apático ou mesmo conformado com os rumos trágicos delineados pela crise ecológica contemporânea" (SARLET; FENSTERSEIFER, 2017, p. 159).

Todavia, mesmo que a Constituição não tenha trazido a participação ambiental expressamente, abriu-se uma brecha que sustenta legalmente a participação da sociedade civil, ao reconhecer o direito que têm os cidadãos ao meio ambiente ecologicamente equilibrado, bem como do dever do Poder Público e da coletividade de defender e preservá-lo (CAMPELlO, 2014). Nesse sentido, “depreende-se o dever da sociedade de participar não somente através da pressão e interlocução com o poder público, mas também com ações cotidianas individuais no intuito de garantir esse direito eminente" (CAMPELLO, 2014, p. 95).

Portanto, não restam dúvidas de que, no ordenamento jurídico brasileiro, a participação em matéria ambiental enquadra-se como um direito-dever do cidadão, podendo ser fundamentada no artigo 1 , inciso II e parágrafo único ${ }^{13}$ - que trazem a democracia participativa enquanto fundamento do Estado de Direito - nos direitos políticos afirmados no artigo 14 e, por fim, também no próprio artigo 225 da CF/88.

Ante o exposto, a participação pública ambiental nos processos de tomada de decisão pode "[...] ser caracterizada como um dever inerente à condição político-jurídica de cidadão, inclusive levando em conta a concepção de uma cidadania ambiental ou ecológica" (SARLET; FENSTERSEIFER, 2018, p. 431). Com efeito, Sarlet e Fensterseifer (2018, p. 431) reconhecem que "a passividade e a inércia política do cidadão, quando confrontado com

13 Art. $1^{\circ}$ A República Federativa do Brasil, formada pela união indissolúvel dos Estados e Municípios e do Distrito Federal, constitui-se em Estado Democrático de Direito e tem como fundamentos: [...] II - a cidadania; [...] Parágrafo único. Todo o poder emana do povo, que o exerce por meio de representantes eleitos ou diretamente, nos termos desta Constituição. 
uma situação concreta de lesão ou ameaça de lesão ao ambiente, contrariam o regime jurídicoconstitucional delineado pelo art. 225 da CF/88”.

Dessa forma, a participação em matéria ambiental apresenta-se como direito-dever do cidadão e como um meio democrático para demandar a tutela do meio ambiente ecologicamente equilibrado, bem como para cumprir com seu dever constitucional de proteger e defender o meio ambiente para as presentes e futuras gerações, permitindo que o indivíduo exija do Estado uma postura que respeite os valores ecológicos.

No ordenamento brasileiro, a participação ambiental pode se dar nas três esferas. No âmbito Legislativo (federal, estadual ou municipal), à luz da CF/88, “o cidadão, ou grupo de cidadãos, podem participar na gestão da coisa pública, propondo leis, ou sugerindo mudanças nas já existentes" (CAMPELLO, 2014, p. 98); outra forma de participação expressa-se por meio dos processos consultivos ao povo, como o plebiscito e o referendo.

Ainda, também se destacam as Comissões do Meio Ambiente que existem, de modo permanente, na Câmara e no Senado Federal, funcionando como "órgãos técnicos encarregados de analisar, avaliar e decidir sobre todas as propostas de novas leis. Vale dizer que essas Comissões também existem nos legislativos estaduais e municipais e servem de fórum para discussões de interesse da sociedade" (CAMPELLO, 2014, p. 98).

No contexto do Judiciário, o cidadão pode atuar tanto de forma individual quanto por intermédio de organizações não governamentais por meio de denúncias que podem ser apresentadas ao Ministério Público, existindo inúmeras ações que podem ser utilizadas na defesa do meio ambiente, como, por exemplo, a Ação Popular e a Ação Civil Pública (CAMPELLO, 2014).

Já no que concerne ao Executivo, a participação ambiental cidadã torna-se visivelmente importante nos Conselhos de Meio Ambiente existentes na esfera federal (Conselho Nacional do Meio Ambiente - CONAMA), estadual (Conselhos Estaduais do Meio Ambiente - COEMAS e CONSEMAS) e municipal (Conselhos Municipais do Meio Ambiente - CONDEMAS) (CAMPELLO, 2014).

Logo, o ordenamento jurídico brasileiro tem instrumentos que podem ser utilizados para viabilizar a participação ambiental, a qual se apresenta como ponto chave da democracia, principalmente, no que tange à busca da melhora progressiva do meio ambiente ecologicamente equilibrado. Do mesmo modo, a participação destaca-se no processo de desenvolvimento sustentável, pois “a ideia que se apreende é que a busca da sustentabilidade 
deve partir da incorporação do preceito da participação pública em processos de gestão dos recursos ambientais" (CAMPELLO, 2014, p. 95).

Importa destacar que, tendo os entes federativos competência constitucional ${ }^{14}$ comum $^{1}$ e concorrente no que concerne à proteção do meio ambiente, o legislador constituinte prezou pela descentralização do poder político, possibilitando a criação de mecanismos capazes de aproximar os cidadãos das instâncias políticas e dos processos de tomada de decisão, com o propósito de fomentar a participação cidadã em matéria ambiental.

Por conseguinte, ao discutir questões ambientais no contexto do ordenamento urbano com o propósito de estruturar cidades sustentáveis, é de grande relevância pensar globalmente e agir localmente. Nesse sentido, a participação pública no âmbito municipal é fundamental, pois é a população de cada localidade que tem maior conhecimento das demandas ambientais de sua região, fazendo com que essa possa identificar, com mais facilidade, o problema e exigir respostas por parte do Poder Público.

Nessa perspectiva, os municípios devem incorporar práticas participativas em suas políticas e legislações, com o propósito de harmonizar as questões ambientais locais com os interesses sociais e econômicos. Com efeito, a participação pública no Plano Diretor, enquanto instrumento de desenvolvimento urbano obrigatório para cidades com mais de vinte mil habitantes, previsto no âmbito constitucional (artigo 182, $\S^{\circ}$ da $\mathrm{CF} / 88$ ) e infraconstitucional (Lei n. 10.257/2001), pode colaborar para que as cidades incorporem os valores da sustentabilidade.

Em 2001, o capítulo da CF/88 sobre política urbana foi regulamentado pelo Estatuto da Estatuto da Cidade (Lei n. 10.257/2001), colaborando para a implementação de políticas focadas na redução da desigualdade social, na construção democrática das cidades e na proteção do meio ambiente; para tanto, o parágrafo único do seu artigo $1^{\circ}$ dispõe que o diploma legal "estabelece normas de ordem pública e interesse social que regulam o uso da propriedade urbana em prol do bem coletivo, da segurança e do bem-estar dos cidadãos, bem como do equilíbrio ambiental" (BRASIL, 2001).

Ainda, a referida legislação coloca como objetivo da política urbana o desenvolvimento das funções sociais da cidade, tendo elencado, no rol de suas diretrizes

14 Conforme salientam Sarlet e Fensterseifer (2017, p. 49) ao tratar da competência constitucional dos entes federativos, "todos os entes federativos são 'chamados' pela CF/88 a atuarem legislativa e administrativamente nas matérias basilares da nossa estrutura político-normativa, entre elas a proteção do meio ambiente”. 
gerais, a sustentabilidade no contexto das urbano (artigo 2 , I) ${ }^{15}$, a gestão democrática por meio da participação (artigo 2, II) ${ }^{16}$, a proteção, preservação e recuperação do meio ambiente (artigo $2, \mathrm{XII})^{17}$ e um planejamento urbano que corrija e evite distorções do crescimento urbano que causem impactos negativos no meio ambiente (artigo 2 , IV) ${ }^{18}$.

Com efeito, não há dúvidas quanto à importância de harmonizar as questões ambientais, sociais e econômicas no contexto das cidades sustentáveis. Desse modo, o Plano Diretor Municipal, enquanto instrumento do ordenamento urbano, deve ser norteado pelas diretrizes e pelos objetivos estabelecidos pela $\mathrm{CF} / 88$, no artigo 182, e pelo Estatuto da Cidade.

No que tange à participação na elaboração no Plano Diretor Municipal, o Estatuto da Cidade a reconhece expressamente no artigo $40, \S 4^{\circ}$, II e III ${ }^{19}$, ao determinar que os poderes Legislativo e Executivo municipais devem assegurar a participação informada da população e de associações representativas dos inúmeros segmentos da comunidade. Assim, a garantia da participação popular durante todo o processo de gestação da política urbana, desde a concepção até a implementação do Plano Diretor e das leis específicas, é uma condição jurídica de validade dos planos aprovados (GUIMARAENS, 2010).

Logo, na busca de soluções para as problemáticas ambientais no âmbito das cidades, a participação coloca-se como um imperativo, permitindo que a população possa demandar a proteção do meio ambiente no contexto urbano e, por conseguinte, construir, conjuntamente

15 I - garantia do direito a cidades sustentáveis, entendido como o direito à terra urbana, à moradia, ao saneamento ambiental, à infra-estrutura urbana, ao transporte e aos serviços públicos, ao trabalho e ao lazer, para as presentes e futuras gerações;

16 II - gestão democrática por meio da participação da população e de associações representativas dos vários segmentos da comunidade na formulação, execução e acompanhamento de planos, programas e projetos de desenvolvimento urbano;

17 Art. $2^{-}$A política urbana tem por objetivo ordenar o pleno desenvolvimento das funções sociais da cidade e da propriedade urbana, mediante as seguintes diretrizes gerais: XII - proteção, preservação e recuperação do meio ambiente natural e construído, do patrimônio cultural, histórico, artístico, paisagístico e arqueológico;

18 Art. $2^{-}$A política urbana tem por objetivo ordenar o pleno desenvolvimento das funções sociais da cidade e da propriedade urbana, mediante as seguintes diretrizes gerais: IV - planejamento do desenvolvimento das cidades, da distribuição espacial da população e das atividades econômicas do Município e do território sob sua área de influência, de modo a evitar e corrigir as distorções do crescimento urbano e seus efeitos negativos sobre o meio ambiente; [...].

19 Art. 4. [...] $\S 4^{\circ}$ No processo de elaboração do plano diretor e na fiscalização de sua implementação, os Poderes Legislativo e Executivo municipais garantirão: I - a promoção de audiências públicas e debates com a participação da população e de associações representativas dos vários segmentos da comunidade; II - a publicidade quanto aos documentos e informações produzidos; III - o acesso de qualquer interessado aos documentos e informações produzidos. 
com os poderes Legislativo e Executivo, diretrizes para o alcance da sustentabilidade no âmbito das cidades.

Em termos práticos, a participação popular pode se dar pela promoção de debates e audiências públicas, em que os cidadãos têm a possibilidade de apresentar suas reivindicações e dar sugestões com base no que gostariam que fosse regulamentado pelo Plano Diretor, permitindo, desse modo, a tutela do interesse da coletividade. Nesse passo, a participação pública, pautada no direito-dever do cidadão ao meio ambiente, materializa-se na discussão dos aspectos ambientais que devem constar no Plano Diretor da cidade; como exemplo, podese citar a criação das áreas de preservação permanente em zonas urbanas e outras zonas de interesse ambiental, visando a proteção das áreas verdes existentes, as nascentes de rios e córregos, no perímetro urbano e de expansão urbana municipal.

Ainda, salienta-se que, o Estatuto da Cidade, ao prever a revisão do Plano Diretor pelo menos a cada dez $\operatorname{anos}^{20}$, reforça a ideia de periodicidade da participação cidadã, possibilitando que os interesses da coletividade, que podem ser objeto de mudança no transcorrer do tempo, sejam constantemente considerados e incorporados na organização do ordenamento urbano.

Portanto, por intermédio da participação o cidadão pode, simultaneamente, buscar a tutela do meio ambiente e cumprir com seu dever fundamental de protegê-lo e defendê-lo para as presentes e futuras gerações; não havendo dúvidas de que a construção de cidades pautadas nos valores de sustentabilidade demanda, necessariamente e constantemente, uma postura proativa seus cidadãos.

\section{CONCLUSÃO}

O desenvolvimento das cidades no mundo, verificado a partir da Revolução Industrial devido ao progresso econômico e à migração populacional do campo para a cidade, deu-se de maneira desordenada, o que colaborou para o desencadeamento de externalidades ambientais que se manifestam no ordenamento urbano. Do mesmo modo, no Brasil, o processo de urbanização ocorreu sem o devido planejamento, colaborando para o surgimento de problemas ambientais no contexto das cidades brasileiras, em que se destacam a falta de

${ }^{20}$ Art. $39, \S 3^{\circ}$ A lei que instituir o plano diretor deverá ser revista, pelo menos, a cada dez anos. 
acesso à água potável e saneamento básico, ausência de instrumentos adequados para o manejo dos resíduos sólidos, assentamentos urbanos informais e o aumento da poluição atmosférica; demonstrando grande descompasso entre o progresso econômico, o desenvolvimento social e a degradação ambiental.

Tais problemáticas implicam diretamente no bem-estar da população e na garantia de sua dignidade, sendo necessário buscar, no âmbito das cidades, a tutela do direito fundamental ao meio ambiente e a harmonização dos fatores sociais, ambientais e econômicos. Nesse sentido, a participação pública destaca-se enquanto importante ferramenta no processo de desenvolvimento sustentável do ordenamento urbano e na busca da tutela do direito fundamental ao meio ambiente de seus cidadãos.

Com efeito, incorporar mecanismos participativos, como audiências públicas e debates, na elaboração do Plano Diretor Municipal coloca-se como um imperativo, permitindo que a população possa tanto cumprir com seu dever constitucional de proteger e defender o meio ambiente quanto demandar a sua proteção no contexto urbano e, por conseguinte, construir, conjuntamente com os poderes Legislativo e Executivo, diretrizes para o alcance da sustentabilidade no âmbito das cidades.

Assim, o alcance do "status" de sustentável pelos ordenamentos urbanos passa, necessariamente, pelo processo de participação pública, em que o cidadão, com as devidas informações, atua de modo ativo em prol da proteção do interesse da coletividade e da tutela do meio ambiente, colaborando com o propósito de equilibrar os fatores que compõem o tripé do desenvolvimento sustentável.

\section{REFERÊNCIAS BIBLIOGRÁFICAS}

ANTUNES, Paulo de Bessa. Direito Ambiental. 12 ${ }^{\mathrm{a}}$ ed. Rio de Janeiro: Editora Lumen Juris, 2010.

BOBBIO, Norberto. A Era dos Direitos. 27 ed. Rio de Janeiro: Elsevier, 2004.

BRASIL. Constituição da República Federativa do Brasil. 1988.

BRASIL. Lei n. 6.938/81 (Política Nacional do Meio Ambiente). 1981.

BRASIL. Lei n. 11.257/2001 (Estatuto da Cidade). 2001. 
CAMPELLO, Lívia Gaigher Bósio. Direito, meio ambiente e políticas públicas: o combate ao fenômeno da desertificação. São Paulo: Clássica Editora, 2014.

CAMPELLO, Lívia Gaigher Bósio; SILVEIRA; Vladmir Oliveira da. Educação para o desenvolvimento sustentável (EDS) e o greening das universidades. Revista Thesis Juris, São Paulo, v. 5, n. 2, 2016, pp. 549-572.

CAVALAZZI, Rosângela Lunardelli. O estatuto epistemológico do Direito Urbanístico Brasileiro: possibilidades e obstáculos na tutela do direito à cidade. In: COUTINHO, Ronaldo;

DUARTE, Marise Costa de Souza. O Direito à Cidade e o Direito às Cidades Sustentáveis No Brasil: $O$ Direito à Produção e Fruição e o Espaço e o Enfrentamento do Déficit de Implementação. FIDES, Natal, v. 6, n. 1, jan./jun. 2015.

G1 SP. Dia vira 'noite' em SP com frente fria e fumaça vinda de queimadas na região da Amazônia. Disponível em <https://g1.globo.com/sp/sao-paulo/noticia/2019/08/19/dia-viranoite-em-sao-paulo-com-chegada-de-frente-fria-nesta-segunda.ghtml> Acesso em 23 set 2020

GUIMARAENS, Maria Etelvina B. A participação na revisão dos Planos Diretores. Coleção Cadernos da Cidade, n. 17. CIDADE - Centro de Assessoria e Estudos Urbanos. Jan. 2010.

IBGE. Frotas de veículos. [online]. Disponível em <https://cidades.ibge.gov.br/brasil/pesquisa/22/28120>. Acesso em 21 set. 2020.

IBGE. Disponível em <https://cidades.ibge.gov.br/brasil/panorama> Acesso em 21 set 2020.

IBGE EDUCA. População Rural $e$ Urbana. Disponível em $<$ https://educa.ibge.gov.br/jovens/conheca-o-brasil/populacao/18313-populacao-rural-eurbana.html> Acesso em 24 set 2020.

INPE. Queimadas. Disponível em <http://queimadas.dgi.inpe.br/queimadas/portalstatic/situacao-atual/> Acesso em 23 set 2020.

IPEA. Resíduos sólidos urbanos no Brasil: desafios tecnológicos, políticos e econômicos. [online]. 09 jul. 2020. Disponível em <https://www.ipea.gov.br/cts/pt/central-deconteudo/artigos/artigos/217-residuos-solidos-urbanos-no-brasil-desafios-tecnologicospoliticos-e-economicos>. Acesso em 21 set. 2020.

LEFEBVRE, Henri. Espaço e Política. Trad. de ANDRADE, Margarida Maria e MARTINS, Sérgio. Belo Horizonte: Editora UFMG, 2008.

MINISTÉRIO DA SAÚDE. Mortes devido à poluição aumentam 14\% em dez anos no Brasil. Disponível em <https://www.saude.gov.br/noticias/agencia-saude/45500-mortes-devido-apoluicao-aumentam-14-em-dez-anos-no-

brasil\#: :text=No\%20Brasil\%2C\%20as\%20mortes\%20em,para\%2044.228\%20mortes\%20em \%202016.> Acesso em 23 set 2020. 
MPGO. Assentamentos urbanos informais. [online]. Disponível em <http://www.mpgo.mp.br/portal/news/assentamentos-urbanos-informais\#.X2 OZKhKjIV>.

Acesso em 22 set. 2020.

ONU NEWS. ONU prevê que cidades abriguem 70\% da população mundial até 2050. 19 fev. $2019 . \quad$ Disponível em $<$ https://news.un.org/pt/story/2019/02/1660701\#: :text=ONU\%20prev\%C3\%AA\%20que\%20 cidades\%20abriguem $\% 2070 \% 25 \% 20 \mathrm{da} \% 20$ popula\%C3\%A7\%C3\%A30\%20mundial\%20at\% C3\%A9\%202050,-

BR\&text=Encontro\%20de\%20alto\%20n\%C3\%ADvel\%20da,popula\%C3\%A7\%C3\%A3o\%2 0mundial\%20vive\%20em\%20cidades.>. Acesso em 23 set. 2020.

SARLET, Ingo Wolfgang; FENSTERSEIFER, Tiago. Curso de direito ambiental. Rio de Janeiro: Editora Forense, 2020.

SARLET, Ingo Wolfgang; FENSTERSEIFER, Tiago. Direitos ambientais procedimentais: acesso à informação, à participação pública na tomada de decisão e acesso à justiça em matéria ambiental. Novos Estudos Jurídicos, v. 23, n. 2, 2018.

SARLET, Ingo Wolfgang; FENSTERSEIFER, Tiago. Princípios do direito ambiental. 2 ed. São Paulo: Saraiva, 2017.

SILVEIRA, Vladmir Oliveira da; ROCASOLANO, Maria Mendez. Direitos Humanos: conceitos, significações e funções. São Paulo: Saraiva, 2010.

SNIS. Esgotamento sanitário 2018. [S. 1.]. 2018. Disponível em <http://snis.gov.br/painelinformacoes-saneamento-brasil/web/painel-esgotamento-sanitario >. Acesso em 22 set. 2020.

SINIS. Manejo de resíduos sólidos urbanos - 2018. [online]. Disponível em <http://snis.gov.br/painel-informacoes-saneamento-brasil/web/painel-residuos-solidos >

Acesso em 22 set. 2020.

TRATA BRASIL. $\quad$ Esgoto. Disponível em <http://www.tratabrasil.org.br/saneamento/principais-estatisticas/no-brasil/esgoto> Acesso em 23 set 2020 .

VELASCO, Clara. Menos de 100 cidades brasileiras estão perto de atingir a universalização do saneamento básico, aponta estudo. [online]. 05 de jun. 2020. Disponível em <https://g1.globo.com/economia/noticia/2020/06/05/menos-de-100-cidades-brasileiras-estaoperto-de-atingir-a-universalizacao-do-saneamento-basico-aponta-estudo.ghtml>. Acesso em 21 set. 2020.

WORLD HEALTH ORGANIZATION. Air pollution. Disponível em $<$ https://www.who.int/news-room/air-pollution> Acesso em 23 set 2020. 